Review Article

\title{
Meaning-making in occupational therapy interventions: a scoping review ${ }^{1}$
}

\section{A construção de sentidos nas intervençóes em terapia ocupacional: uma revisão de escopo}

Ana Carolina Carreira de Mello ${ }^{a}$ (D), Angélica da Silva Araujo ${ }^{a}$ (D), Ana Lucia Borges da Costab (D), Taís Quevedo Marcolino ${ }^{a}$ (D)

${ }^{a}$ Universidade Federal de São Carlos - UFSCar, São Carlos, SP, Brasil.

${ }^{\text {bS }}$ chool of Sport \& Health Sciences, University of Central Lancashire - UCLan, Preston, United Kingdom.

How to cite: Mello, A. C. C., Araujo, A. S., Costa, A. L. B., \& Marcolino, T. Q. (2021). Meaning-making in occupational therapy interventions: a scoping review. Cadernos Brasileiros de Terapia Ocupacional, 29, e2859. https://doi.org/10.1590/2526-8910.ctoAR2158

\begin{abstract}
Introduction: Meaning-making is an experience-centred process. It is an essential element for understanding the impact of occupational therapy interventions focused on fostering processes of becoming, one of the four integrated dimensions of meaningful occupation (along with doing, being, and belonging). Objective: This paper aims to explore further some of the aspects that are essential for meaningmaking in occupational therapy interventions. Method: A scoping review guided by Arksey and O'Malley's methodological framework was conducted. In the initial search, 528 articles were retrieved from three databases; 16 met the criteria for inclusion: articles in English, peer-reviewed, published between January 2008 and December 2017, that addressed some type of occupational therapy intervention, with data related to the meanings of the participants of the studies. Results: The articles address a multiplicity of populations, services, and fields of practice, in qualitative studies, with methodologies that prioritise reflection on the lived experience. Thematic analysis highlights the interconnection between being, doing, and belonging to foster meaning-making; implications of professional actions; and meaning-making triggered by reflective processes. Conclusion: Meaning-making demands reflection on the lived experience, and is influenced by human and physical environments. Both conditions/limitations and new skills/abilities enhance processes of meaning-making. Implications for future research are considered.
\end{abstract}

Keywords: Occupational Therapy/Trends, Professional Practice, Review.

\section{$\underline{\text { Resumo }}$}

Introduçáo: A construção de sentidos é um processo centrado na experiência, essencial para a compreensão do impacto das intervençôes em terapia ocupacional

${ }^{1}$ This paper is part of the master's thesis of the first author, under the guidance of the last author. 
voltadas para a promoção de processos de transformação/becoming, uma das quatro dimensóes integradas da ocupação significativa (juntamente com o fazer/doing, ser/being e pertencer/belonging). Objetivo: Este artigo tem como objetivo identificar aspectos essenciais para a construção de sentido em intervençôes de terapia ocupacional. Método: Foi realizada uma revisão de escopo. $\mathrm{Na}$ busca inicial, 528 artigos foram recuperados de três bases de dados; 16 atenderam aos critérios de inclusão: artigos em inglês, revisados por pares, publicados entre janeiro de 2008 e dezembro de 2017, que abordassem algum tipo de intervenção de terapia ocupacional, com dados referentes aos sentidos construídos pelos participantes dos estudos. Resultados: Os artigos abordam múltiplas populaçôes, serviços e campos de prática, em estudos qualitativos, com metodologias que priorizam a reflexão sobre a experiência vivida. A análise temática destaca a interconexão entre ser, fazer e pertencer para promover a construção de sentido; implicaçôes para açóes profissionais; e construção de sentido desencadeada por processos reflexivos. Conclusáo: A construção de sentidos demanda reflexão sobre a experiência vivida, é influenciada pelos ambientes humanos e físicos. Tanto as condiçôes limitantes como as novas habilidades adquiridas desencadeiam processos de construção de sentido. Implicações para pesquisas futuras são indicadas.

Palavras-chave: Terapia Ocupacional/Tendências, Prática Profissional, Literatura de Revisão.

\section{Introduction}

Meaning can be understood as an aspect of human subjectivity connected to singular experiences that is in constant movement, being evaluated in importance and value based on global and singular influences (Eakman, 2013; Gruhl, 2017; Ikiugu \& Pollard, 2015; Ulfseth et al., 2015; Roberts \& Bannigan, 2018; Roepke et al., 2014). Meaning-making is an essential experience-centred process for understanding the effectiveness of occupational therapy interventions focused on fostering processes of becoming toward meaningful occupations or on what can be found as meaningful in life (Ikiugu \& Pollard, 2015; Mello et al., 2020). While research on meaning has been increasing in recent decades, especially in relation to its connection with health and well-being (Eakman, 2013; Roepke et al., 2014), there is a lack of review studies on meaning-making.

Roepke et al. (2014) found three general related constructs to meaning that emerged from a literature review. One construct theorizes meaning as comprising a set of feelings, goals, and beliefs that shape our interpretations of the world, giving us a sense of a meaningful life. Another construct relates meaning to the purpose of our actions towards a desired goal, which can be understood as an aspect of belonging connected to something greater than the self (Eakman, 2013; Roepke et al., 2014). These conceptions are fundamental for understanding clients' motivations, beliefs, and values, which is an essential professional skill (Mattingly, 1998; Zafran, 2020). Nevertheless, these conceptions unveil meanings that people already possess or experience (Roepke et al., 2014).

Occupational therapy clients usually experience difficult situations that challenge their "[...] sense of coherence or subjective meaningfulness" (Roepke et al., 2014, p. 3). Much of 
occupational therapists' work lies in shaping experiences that may become meaningful for clients, "[...] to make therapy a time which is about 'becoming', about transformation" (Mattingly, 1998, p. 64). This brings us to the third construct related to meaning: meaning-making as a process of "[...] searching for meaning or reappraising the meaning of something" (Roepke et al., 2014, p. 3). The process of meaning-making leads individuals to change their experience of meaning and to reconsider what really matters in life (Mattingly, 1998; Zafran, 2020). Gruhl (2017) highlighted that meaning-making of participation in occupations can reveal both expected and unforeseen outcomes, indicating that, in this process, new meanings can emerge. Mattingly (1998) discusses that the meaning is not based on an experience itself. To uncover the emerging meaning, we need to recognise the dynamic interplay between cultural and situated contexts, which offer ways to interpret private meanings (Mattingly, 1998; Ulfseth et al., 2015).

A 'becoming' time is strongly facilitated by the transformation of meaning perspectives, structures based on premises and beliefs in which new experiences are interpreted (Dubouloz, 2014). Becoming can be understood as a triggered process when people face new situations and need to envision possible other futures through the exploration of new possibilities that can fill their life with meaning (Hammell, 2004; Hitch et al., 2014a; Wilcock, 2006). In the occupational therapy literature, becoming is one of the four integrated dimensions of meaningful occupation, as well as doing, being and belonging. The interaction between these four dimensions (Wilcock, 2006) has recently been explored, shedding light on the complexity of the phenomena related to doing activities in life and the multidimensional nature of occupation (Hitch et al., 2014a). It has been advocated that a "[...] holistic perspective that encompasses all of the dimensions" (Hitch et al., 2014b, p. 260) is needed to advance occupational therapy practice.

Ideally, occupational therapy interventions should be aimed at an integration of doing, being and belonging to foster becoming. Studies on interventions can reveal important aspects of how professionals sustain becoming processes and how becoming relates to meaning-making. Seeking a deeper comprehension of these aspects, a scoping review was conducted to summarise, describe and identify possible gaps in the existing literature on meaning-making in occupational therapy interventions.

\section{Method}

Using the five-step framework proposed by Arksey \& O’Malley (2005), a scoping review was conducted. The purpose of a scoping study is to rapidly map the key concepts underpinning a research area, the main sources and the types of evidence available, especially in complex areas that have not been thoroughly reviewed (Arksey \& O’Malley, 2005). The five-step methodological framework includes: 1) identification of the research questions; 2) identification of relevant studies; 3) study selection; 4) data extraction; and 5) data synthesis.

\section{Identifying the research question}

The guiding question for this study was: What elements are essential for meaningmaking in occupational therapy interventions? In order to render a more contemporary picture, this review adopted a 10 -year time frame. 


\section{Identifying the relevant studies}

The keywords, which were identified with the assistance of a librarian from the Federal University of São Carlos, were 'occupational therapy', 'meaning', 'meaning making', 'meaning-making', combined with the boolean operator 'and'. The databases searched were PsycINFO, PubMed and Scopus. Gray literature was not included. The search results were imported into EndNote ${ }^{\odot}$ Web online software, where duplicate studies were removed. All search procedures and results were documented.

\section{Study selection}

As the objective of this review was to identify essential elements for the meaningmaking process in occupational therapy interventions, were sought articles addressing these elements through the contribution of the clients who received the intervention. Thus, the inclusion criteria included: articles in English; articles peer-reviewed; articles addressing some type of occupational therapy intervention and whose data relates to clients' meanings; and articles published from January 2008 to December 2017. The exclusion criteria were: literature reviews, non-empirical studies, books, annals, editorials and gray literature.

The search terms were identified in the titles, abstracts, keywords, and/or the full texts of the articles found. After reviewing the 528 abstracts, 29 articles were selected by two reviewers (first and last authors), and the second author cross checked the study selection for accuracy (Table 1). After a complete reading of the studies, 16 were included in the scoping review.

Table 1. Study selection and inclusion.

\begin{tabular}{|c|c|c|}
\hline Databases & $\begin{array}{l}\text { Search terms } \\
\end{array}$ & Results \\
\hline \multirow[b]{2}{*}{$\begin{array}{l}\text { PubMed (National } \\
\text { Library of Medicine) }\end{array}$} & 'occupational therapy' (all fields) and 'meaning' (all fields) & 165 \\
\hline & $\begin{array}{l}\text { 'occupational therapy' (all fields) and 'meaning-making' } \\
\text { (all fields) }\end{array}$ & 8 \\
\hline \multirow[b]{2}{*}{ PsycINFO (APA) } & any field: 'occupational therapy' and any field: 'meaning' & 248 \\
\hline & $\begin{array}{c}\text { any field: 'occupational therapy' and any field: 'meaning- } \\
\text { making' }\end{array}$ & 17 \\
\hline \multirow[t]{9}{*}{ Scopus (Elsevier) } & $\begin{array}{c}\text { title-abs-key ('occupational therapy') and title-abs-key } \\
\text { ('meaning') }\end{array}$ & 191 \\
\hline & $\begin{array}{c}\text { title-abs-key ('occupational therapy') and title-abs-key } \\
\text { ('meaning-making') }\end{array}$ & 10 \\
\hline & Articles identified through databases search $=$ & 639 \\
\hline & Duplicate articles removed $=$ & 111 \\
\hline & Results after duplicates removed $=$ & 528 \\
\hline & Articles excluded after title and abstract screened $=$ & 499 \\
\hline & Full text assessed for eligibility $=$ & 29 \\
\hline & Articles excluded after full text screened $=$ & 13 \\
\hline & Studies included in the scoping review $=$ & 16 \\
\hline
\end{tabular}




\section{Charting the data}

A spreadsheet was developed for the extraction of the following data: year of publication; study title; author(s); institutional affiliation of the author(s); country where the intervention was developed; journal title; database; keywords; location and type of intervention; field of practice; type of research; design of study; materials and methods; goals; target population; sample; whether the intervention was specific to occupational therapy or conducted by a multi-professional team including occupational therapy; intervention outcomes and the impact on participants' meaning; study results; conclusions; possible research gaps and/or recommendations for future research.

\section{Collating, summarising, and reporting the results}

A descriptive and a thematic analysis of the articles were undertaken. The descriptive analysis identified the extent, nature, and distribution of the studies. The thematic analysis identified the main categories addressed in the articles. This step was developed iteratively through discussions between the authors.

\section{Results}

Of the 16 articles included in the review, six were published in 2017 (Fletcher, 2017; Leufstadius, 2017; Lund et al., 2017; Nilsson \& Lundgren, 2017; Rijkers-de Boer et al., 2017; Verdonck et al., 2017), one in 2016 (Van't Leven et al., 2016), two in 2015 (Chippendale \& Boltz, 2015; Folan et al., 2015), one in 2013 (Lindström et al., 2013), tree in 2012 (Chiu et al., 2012; Mason \& Conneeley, 2012; Zafran et al., 2012), one in 2010 (Cipriani et al., 2010), one in 2009 (Bazyk \& Bazyk, 2009), and one in 2008 (Dubouloz et al., 2008). Most of the studies were carried out in the USA (4) and in Sweden (4) (see Table 2).

Table 2. Countries.

\begin{tabular}{ccc}
\hline Country & Number & \% \\
\hline USA & 4 & $25 \%$ \\
\hline Sweden & 4 & $25 \%$ \\
\hline Canada & 3 & $19 \%$ \\
\hline Netherlands & 2 & $13 \%$ \\
\hline Australia, South Africa, Iran, UK & 1 & $6 \%$ \\
\hline England & 1 & $6 \%$ \\
\hline Australia & 1 & $6 \%$ \\
\hline
\end{tabular}

Concerning the practice setting of occupational therapy, most of the articles concentrated on the areas of practice of Gerontology (6) (Chippendale \& Boltz, 2015; Cipriani et al., 2010; Fletcher, 2017; Nilsson \& Lundgren, 2017; Rijkers-de Boer et al., 2017; Van't Leven et al., 2016) and Mental Health (4) (Leufstadius, 2017; Lindström et al., 2013; Lund et al., 2017; Zafran et al., 2012), followed by Rehabilitation (3) (Dubouloz et al., 2008; Folan et al., 2015; Verdonck et al., 2017) and Childhood (2) (Bazyk \& Bazyk, 2009; Chiu et al., 2012). Of the 16 articles, 14 were qualitative studies (Chiu et al., 2012; Cipriani et al., 2010; Dubouloz et al., 2008; Folan et al., 2015; Leufstadius, 2017; Lindström et al., 2013; Lund et al., 2017; Mason \& 
Conneeley, 2012; Nilsson \& Lundgren, 2017; Rijkers-de Boer et al., 2017; Bazyk \& Bazyk, 2009; Van't Leven et al., 2016; Verdonck et al., 2017; Zafran et al., 2012) and two were mixedmethod (Chippendale \& Boltz, 2015; Fletcher, 2017). For data collection, eight studies used interviews as their exclusive method (Dubouloz et al., 2008; Folan et al., 2015; Leufstadius, 2017; Lund et al., 2017; Nilsson \& Lundgren, 2017; Van't Leven et al., 2016; Verdonck et al., 2017; Zafran etal., 2012); six used interviews combined with other methods - Likert scale questionnaire, field observations, field notes (Chiu et al., 2012; Cipriani et al., 2010; Fletcher, 2017; Lindström et al., 2013; Rijkers-de Boer et al., 2017; Bazyk \& Bazyk, 2009); one used the Presence subscale of the Meaning in Life Questionnaire (MLQ-Presence) (Chippendale \& Boltz, 2015); and one used only focus groups (Mason \& Conneeley, 2012).

Nine of the studies were specifically about occupational therapy intervention (Chippendale \& Boltz, 2015; Chiu et al., 2012; Cipriani et al., 2010; Dubouloz et al., 2008; Fletcher, 2017; Lund et al., 2017; Nilsson \& Lundgren, 2017; Bazyk \& Bazyk, 2009; Zafran et al., 2012), five of them were multiprofessional (Folan et al., 2015; Leufstadius, 2017; Lindström et al., 2013; Rijkers-de Boer et al., 2017; Van't Leven et al., 2016) and it was not possible to identify this distinction in two of them (Mason \& Conneeley, 2012; Verdonck et al., 2017). The studies took place in different services and contexts, but four of them were developed in community centers (Chippendale \& Boltz, 2015; Fletcher, 2017; Rijkers-de Boer et al., 2017; Bazyk \& Bazyk, 2009) and three at home (Chiu et al., 2012; Dubouloz et al., 2008; Verdonck et al., 2017) (see Table 3).

Table 3. Places of intervention.

\begin{tabular}{ccc}
\hline Places & Number & \% \\
\hline Community center & 4 & $25 \%$ \\
\hline Domicile & 3 & $19 \%$ \\
\hline Unidentified & 3 & $19 \%$ \\
\hline Psychiatric service & 1 & $6 \%$ \\
\hline Early Intervention Program for Psychosis & 1 & $6 \%$ \\
\hline Settlement & 1 & $6 \%$ \\
\hline Day center & 1 & $6 \%$ \\
\hline Long term care for seniors & 1 & $6 \%$ \\
\hline Rehabilitation service & 1 & $6 \%$ \\
\hline
\end{tabular}

Table 4 presents the descriptions of the participants and the interventions carried out. The results of the selected studies are discussed in the qualitative findings section.

Table 4. Descriptions of the interventions.

\begin{tabular}{ccc}
\hline Article & Participants & Intervention \\
\hline & & $\begin{array}{c}\text { A three-phase intervention was } \\
\text { carried out with four Day Center }\end{array}$ \\
Leufstadius (2017) & $\begin{array}{c}\text { 11 users of the Day Centers, } \\
\text { aged 32 to 63. }\end{array}$ & $\begin{array}{c}\text { 1) Educational training focusing on } \\
\text { research data and theory on } \\
\text { meaningful occupation; }\end{array}$ \\
\hline
\end{tabular}


Table 4. Continued...

\section{Article}

Lund et al. (2017)

Fletcher (2017)

10 elderly adults, over 75 years old.

\section{Intervention}

2) Workshops to identify gaps and good practices regarding meaningful occupation in the Day Centers;

3) Formulation of goals and strategies by the professionals in collaboration with service users.

A group intervention called "The Balancing Everyday Life" was carried out for 12 weeks. Participants reflected and talked with others about their involvement in meaningful daily occupations and how to find a balance, through lectures, study material, group discussions, and activities. Each member set personal goals related to the topic of each week and did self-assigned homework.

Participants received a kind of assistive technology called

"Environmental Control System", which was fitted in their homes according to their preferences.

In biweekly groups, the participants developed 7 activity projects: a memory book used to store photographs and other souvenirs; a digital media disc with photographs; an autobiographical voice box; manual modeling/sculpture; origami folding with special papers; a selfportrait painting on canvas; and a time capsule, created from an old book. Each participant developed their own activities but they were asked to do them around the same table.

8 group sessions focusing on health promotion, based on social activities,

physical activities, meaningful

Nilsson \& Lundgren (2017)
19 elderly adults, over 77 years old. participation, and good eating habits. The participants chose the activities to address each theme.

10 group sessions focusing on the meaning of daily activities to foster self-perception of health and well- 
Table 4. Continued...

\section{Article}

Van't Leven et al. (2016)

Chippendale \& Boltz (2015)

39 people, community residents, over 60 years old.
34 persons/people with dementia and caregiver dyads.

\section{Intervention}

3 intervention proposals, in a total

of 6 to 10 home sessions, were conducted: Pleasant Events

Program, Exercise Intervention and

Support for People with Dementia and their Caregivers and Occupational Therapy. Several activities were carried out jointly by the dyads. Psychoeducation and emotional care to promote adaptation to the effects of dementia were conducted.

Two-step intervention:

First the elderly attended weekly life review writing workshops for 8 weeks. Writing instruction was offered to favor writing in chronological order about how life experiences shaped who they were (control group).

Two weeks later, some of these elderly people, chosen at random, attended an intergenerational program composed by them and by students of health sciences, with weekly meetings, for 4 weeks.

7 people with spinal cord injuries, aged 20 to 45 , users of rehabilitation

services.

Folan et al. (2015)

Lindström et al. (2013)

16 people with psychotic disorders, aged 27 to 66 .

12 dyads of mothers and premature babies. The

Chiu et al. (2012) mothers had an average age

of 33 .
Participants were exposed to the use of assistive technologies to access computers.

The intervention program was based on the Everyday Life Rehabilitation model (a model of home occupational therapy which aims to allow significant daily occupations for people with severe mental illness who live in sheltered or supported homes). Depending on the goals of each participant, the intervention phase ranged from 2 to 17 months.

Weekly home-based occupational therapy sessions, lasting one hour, from a few months to more than one year depending on the clients' needs, with video recordings of motherbaby interactions. 
Table 4. Continued...

\begin{tabular}{|c|c|c|}
\hline Article & Participants & Intervention \\
\hline Mason \& Conneeley (2012) & $\begin{array}{l}6 \text { men aged between } 20 \text { and } \\
60 \text { and their children. }\end{array}$ & $\begin{array}{l}\text { Fathers and children participated } \\
\text { in horticulture/gardening, } \\
\text { handicrafts, and activities in } \\
\text { nature, for four hours, twice a } \\
\text { week, for one year. }\end{array}$ \\
\hline Zafran et al. (2012) & $\begin{array}{l}5 \text { adults, aged } 20 \text { to } 25 \text {, after } \\
\text { a first psychotic episode. }\end{array}$ & $\begin{array}{l}\text { Participants received occupational } \\
\text { therapy treatment, focusing on } \\
\text { academic reintegration. }\end{array}$ \\
\hline Cipriani et al. (2010) & $\begin{array}{c}8 \text { elderly people, over } 65 \\
\text { years old, residents in nursing } \\
\text { homes. }\end{array}$ & $\begin{array}{l}\text { Participants discussed, planned, and } \\
\text { engaged in the altruistic activity of } \\
\text { creating flower arrangements and } \\
\text { greeting cards for local patients receiving } \\
\text { palliative care. }\end{array}$ \\
\hline Bazyk \& Bazyk (2009) & $\begin{array}{l}10 \text { low-income urban youths } \\
\text { attending after-school care } \\
\text { ( } 4 \text { boys and } 6 \text { girls), aged } 7 \text { to } \\
12 .\end{array}$ & $\begin{array}{l}\text { The youths attended a nine-week } \\
\text { after-school program designed as } \\
\text { preventive occupation-based groups } \\
\text { called "Occupational Therapy } \\
\text { Groups for HOPE", offered annually } \\
\text { on the basis of their inherent needs } \\
\text { for structured leisure occupations, } \\
\text { social-emotional learning, and close } \\
\text { human connections. }\end{array}$ \\
\hline Dubouloz et al. (2008) & $\begin{array}{c}10 \text { adults diagnosed with } \\
\text { rheumatoid arthritis, aged } 39 \\
\text { to } 66 .\end{array}$ & $\begin{array}{l}\text { The participants attended a } \\
\text { rehabilitation program focused on the } \\
\text { provision of information, } \\
\text { encouragement of reflection on their } \\
\text { illness, and adaptation of their daily } \\
\text { living environment and activity. The } \\
\text { occupational therapy intervention was } \\
\text { provided at the clients' residences } \\
\text { once a week, and lasted between } 6 \\
\text { and } 12 \text { weeks. }\end{array}$ \\
\hline
\end{tabular}

\section{Doing, being and belonging in interventions}

\section{Doing and belonging}

Studies from the mental health field highlighted the importance of relationships for feeling connection, sharing and belonging. Lund et al. (2017, p. 9) reflected that the feeling of connection through group participation had increased the value of meaning, "[...] feeling less alone, more connected, supported, respected, and worthy". The authors proposed belonging as the first step towards meaning-making in life experiences, pointing out that as participants started feeling secure, they were able to deepen their sharing, as in the excerpt: "Belonging to a group of people who had 'full understanding' and 'were in the same boat' were strong expressions of meaning, as was expanding one's social network" (Lund et al., 2017, p. 6). Lindström et al. (2013, p. 738) highlighted that for people with psychotic disorders, sociability was strongly 
linked to the role practitioners played in participants' lives, in contrast to their loneliness and lack of genuine relationships. The participants talked about "[...] the value of conquering new places, of establishing new relationships, and expanding the notion of their capabilities".

Feeling accepted and recognised by others for their way of being and doing was pointed out by Leufstadius (2017) when evaluating an intervention for improving meaningful occupations in Day Centers (DC). A similar theme was highlighted by Zafran et al. (2012, p. 10), who discussed the acceptance of different performance patterns due to new cognitive or emotional stress thresholds, and the importance of being accepted by family, colleagues, or professional staff for academic reintegration after a first psychotic episode, as seen in the excerpt: "[...] friends significantly encouraged them, saying things such as: 'you're smart, you can do it, you know, just take it one day at a time".

Furthermore Leufstadius (2017), Lindström et al. (2013) and Zafran et al. (2012) criticised that such trust relationships are only found within services and discuss the importance of developing actions to favor and expand the integration of people with mental health issues in society. Reinforcing this idea, Rijkers-de Boer et al. (2017, p. 6), who worked with elderly residents in the community, highlighted the power of positive relationships and mutual recognition in the community as a way to foster solidarity: "Jane, Mary and Harriet recognised something of themselves in the others, creating a solid base for solidarity".

Cipriani et al. (2010, p. 272) explored the experience of elderly people residing in a long-term institution, when planning, participating, and reflecting on their involvement in an altruistic activity. This study promoted the value of doing together on a regular basis in order to foster a sense of belonging amongst participants, as illustrated in the following quote: "[...] through the small gatherings of the participants over a period of several weeks, a feeling of togetherness and belonging appeared to develop". Establishing new and genuine relationships was sometimes considered more important than the intervention itself in three studies (Fletcher, 2017; Mason \& Conneeley, 2012; Nilsson \& Lundgren, 2017).

Reinforcing the connections between doing and belonging to a community, Mason \& Conneeley (2012, p. 234) explored the perspectives of fathers engaged in a horticultural project developed in a deprived area of the United Kingdom. The findings highlighted that the opportunity to interact with other fathers/parents whilst working/doing together was perceived as a vehicle for social change, facilitating a sense of belonging and promoting social integration. A sense of belonging minimised the stigmas associated with their social situations, as stated by one participant: "Some dads, ... they've really taken notice of us all, ... watching us, the way we are with our children and it changes them a little bit to help them with their children. It's really good".

Studying elderly of a group-based occupational therapy intervention, Nilsson \& Lundgren (2017, p. 15) found that meeting new people, talking, sharing experiences, and doing new things together were significant as the content of their intervention about healthy ageing, as in the excerpt that highlights that health tips were more meaningful because they "[...] were shared between participants and (because of) the significance of discussing the tips with peers". Equally, the intervention was valued 
especially for respecting the participants' identities at their perceived age, and not as “[...]'children' nor as 'older than they were" (Nilsson \& Lundgren, 2017, p. 20). Fletcher $(2017$, p. 6) also stated that the social participation provided by the groups of reminiscent activities was more significant to elderly than the memories they were evoking: "They vigorously agreed that they had the most meaningful experiences when they were immersed in actual creation of mementos and living in the moment".

\section{Doing and being: potential for developing new actions and gaining new perspectives}

Doing was highlighted in its importance for developing new roles, learning new skills, and how it creates opportunities to gain a new perspective on life. Folan et al. (2015, p. 49) presented that by learning computer skills, participants re-acquired a sense of control over their lives, from financial control to expanding the possibilities of relating, as is reflected in this statement from a participant: "I keep in contact with everyone in Melbourne. It's kind of like freedom ... because if you can't get out of bed, you can still talk to people". For autonomous and meaningful doing, participants with rheumatoid arthritis in Dubouloz et al. (2008, p. 35) study also highlighted the importance of having a supportive human and physical environment to reduce the impact of the long-term condition on occupation, as can be seen in the statements: 'My husband does what I don't feel like doing' [...] and 'I was still productive at work'. Moreover, the physical environment also had a positive impact on doing. Bazyk \& Bazyk (2009, p. 77) discussed that the physical environment was an element permeated by transformations, and a "just-right environment" demanded careful preparation and consideration of how spaces, materials, and objects can influence the individual or group experience to foster creative engagement.

Creativity, challenge, feasibility, and pleasure are characteristics linked to satisfaction in doing and were important sources of meaning to build personal experiences. Bazyk \& Bazyk (2009, p. 74) highlighted that fun, creativity, and pleasure were found through challenging and achievable occupations, chosen by the person, based on clear objectives in a feedback process, as illustrated by one of the children who participated in the study: "Corey indicated that he liked doing the projects because 'you get to pick whatever you want to put on it"”. Mason \& Conneeley (2012, p. 234) also discussed that enjoyment and freedom can be found in shared occupations or co-occupations with a high degree of interaction, when one person's actions influence and shape others', as is explicit in this excerpt: "The fathers and children engaged in joint motor tasks (physicality), from playing games to making bird feeders, and shared a sense of enjoyment and freedom (emotionality)".

Verdonck et al. (2017, p. 4) discussed that being able to do even simple activities generated satisfaction and pleasure among their participants, contributing to the recognition of themselves, highlighting that "[...] small changes from a practical point of view (turning on a device) is more than simply 'doing something', it also means something and creates feelings of pleasure, safety and an enhanced sense of self". Fletcher $(2017$, p. 6) revealed that the participants defined creativity as meaning "fun 
and enjoyment" and that meaning appeared to be created by engaging in group activities of reminiscence.

Voluntary and altruistic activities were considered meaningful, with emphasis on purposeful activities whose final products expressed the intention of those who made them. Cipriani et al. (2010, p. 272) described an intervention with activities involving altruistic attitudes, such as doing or making something to honor or give to someone or to a group of people. The elderly participants reflected on this aspect as one of the components of doing that is meaningful. They desired that the final product of the activity needed to be beautiful, interesting and inventive, giving the impression that they were especially inspired by the people who would receive it: "It was noted that the gift needed to be 'pretty to look at' and give the impression that 'someone was thinking about them'”. Chippendale \& Boltz (2015, p. 2) discussed the power of participation in voluntary activities as a way of creating meaning in life by providing an "[...] opportunity to contribute to family and society". Voluntary activities were highlighted for their social aspects and for providing moments of sharing stories and opportunities to be a model, contributing to the construction of new occupational identities as volunteers, mentors and educators (Chippendale \& Boltz, 2015).

In terms of doing and being, learning to do activities in different ways has changed feelings and enables the strongest engagement in occupations, diminishing fear and enhancing joy, presence, and relaxation, and allowing the persons to be whole and to have a sense of perspective on life. In a study with mothers and premature babies, Chiu et al. (2012) pointed out that play can be improved through a positive relationship. The interaction between the mother-child dyad has undergone important subjective changes with domiciliary occupational therapy intervention, changing the playing of babies which went from "[...] being fussy and inactive to playful and responsive", while their mothers became more cheerful, going from "fearful to joyful" (Chiu et al., 2012, p. 23).

In their environmental control system study, Verdonck et al. (2017, p. 4) argued that the participants acquired more independence for some activities of daily life without the constant presence of caregivers and the inherent "perpetual obligation" of apologies and thanks; this frees them to experiment with being themselves, in their time, without having their rhythm controlled by another, as this statement indicates: "I can watch five minutes of a program, turn it off, go watch another program, turn that off if I don't like it ... that's what I like about it. That's what; I think it's the freedom and the independence of it". The importance of being whole and relaxed was also emphasised by Leufstadius (2017, p. 7), who found that when participants from Mental Health Day Centers were able to engage in their own way of doing, they "[...] felt that they were accepted and could be relaxed in the group despite their different ways of doing things, behavior and values $[\ldots .$.$] ".$

\section{Professional actions to foster the becoming process}

This theme embraces professional actions recommended to foster meaningful interventions. Professionals must be aware of their role as mentor, model, and leader 
to propose stimulating and inventive activities/occupations, taking into consideration the ages and capabilities of clients (Nilsson \& Lundgren, 2017). Rijkers- de Boer et al. (2017, p. 3) proposed that professional performance should be more focused on the role of facilitator, supporting learning processes, allowing the clients "[...] to make choices and showing care and concern". The facilitator's interaction was not only directly with the clients, but also involved helping other people who interact with clients to acquire skills that helped them to improve the quality of the relationship and to acquire behaviors that lead the client to learn and develop, as explained by Bazyk $\&$ Bazyk (2009, p. 78) when discussing how teachers and caregivers need to "[...] learn how to tune into and respond to children's social-emotional needs on a daily basis".

Zafran et al. (2012) highlighted the need for a long period of time to establish a therapeutic relationship with a young person after their first psychosis episode. This was because the rehabilitation process embraces critical transitional moments that demand the presence of someone who can offer perspectives for the future: “[...] therapeutic relationships can provide these clients with the opportunity to find strategies for success, to continually recreate the narrative of their lived experiences, and to maintain hope" (Zafran et al., 2012, p. 19). Keeping hope was also recommended by Lindström et al. (2013, p. 737), believing that it is "[...] hard to envision someone succeeding in a transformative process without having conceptions about possible improvements in the future. Given a long history of disappointments, sensing hope cannot be taken for granted and needs to be nurtured". Zafran et al. (2012) also highlighted the importance of the professional to be someone who inspires confidence and who can talk about the lived experiences in order to open new possibilities for the future.

\section{Meaning-making process}

The meaning-making process was described as dynamic and unique for each person; and also contextualised socioculturally as well as located in time and place (Leufstadius, 2017). For Zafran et al. (2012), meaning-making is an on-going process of reconstructing one's identity, which situates the meaningfulness of experiences in people's narratives within the events of their daily lives (Leufstadius, 2017), demanding reflection on the lived experience (Cipriani et al., 2010). Meaning-making was also defined as being contextual and relational-based by Van't Leven et al. (2016) based on their work with caregiver-people with dementia dyads. The study highlights the multiplicity of meanings built around what is experienced, as is well expressed in the excerpt: "Making a cup of coffee could mean independency but could also mean caring for the partner, while going for a walk could mean just passing time but could also mean being physically active or having social contact" (Van't Leven et al., 2016, p. 14).

Although the studies have sought to discuss the interventions carried out, the process of meaning-making can be accessed since the researchers employed methodological designs and methods to foster and guarantee opportunities for reflection and dialogue about what was happening, contemplating the perspectives of 
the clients on their lived processes during or after the interventions. Interviews were used by 14 studies to capture the clients' experiences, and not only the content of the interventions themselves. These studies were interested in giving voice to the participants, "[...] to their own interpretations and thoughts" (Bazyk \& Bazyk, 2009, p. 72), and understanding the impact of the intervention from the participants' perspectives (Nilsson \& Lundgren, 2017). Van't Leven et al. (2016, p. 16) pointed out that a significant number of participants with dementia were able to talk about their experiences during occupational therapy intervention. Even those participants in the later stages of dementia "[...] could still indicate what activities were important to them and why" during the interviews.

Studies using other data collection methods (Chippendale \& Boltz, 2015; Mason $\&$ Conneeley, 2012) also sought to preserve possibilities to access reflections on what has been experienced. Studying the meaning of participation in an allotment project for fathers, Mason \& Conneeley (2012, p. 232) used focus groups in order to allow flexibility for the inclusion of emerging data, encouraging the participants to reflect on their "[...] reasons for getting involved in the project and continuing to attend; [...]; if their attendance had changed other areas of their life; [...], and the meaning of attending the allotment". Chippendale \& Boltz (2015), in addition to using the MLQPresence scale for data collection with the elderly, also analysed participants' written feedback about their experiences.

Meaning-making processes were triggered by reflection on health and issues related to specific conditions. Zafran et al. (2012, p. 14) emphasised that learning about psychosis through psychoeducation activities helped the reconstruction of meaning, to the extent of integrating illness information and personal experiences; as they said, "[...] these 'facts' could be incorporated into their self-concept". Dubouloz et al. (2008, p. 36) discussed how health status triggered self-reflection in adults with rheumatoid arthritis "[...] when the course of the illness was acute, and when onset was more severe rather than gradual".

Dubouloz et al. (2008, p. 36) also discussed how the environment of care provided by occupational therapists helped the clients build a new understanding of their limitations and disabilities, leading "[...] to a profound personal change of clients' meaning perspectives”. Furthermore Leufstadius (2017) and Nilsson \& Lundgren (2017) shedded light on the role played by the unexpected, the new, the unusual, as experienced in the intervention as an essential element that triggered meaning-making:

The participants articulated the significance of the intervention with enjoyment, concrete usefulness, togetherness, respect and having gotten a sense of perspective on one's own life. Some of these themes were narrated as being discoveries [...] not expected from the intervention [...] (Nilsson \& Lundgren, 2017, p. 15). 


\section{Discussion}

The descriptive analysis elucidated the multiplicity of populations, services, and fields of practice discussing meaning-making. Gerontology (6) and Mental Health (4) were the two fields with the largest number of studies, all of which were in line with a narrative perspective in occupational therapy (Mattingly, 1998; Ulfseth et al., 2015; Zafran, 2020), imbued with the aim of offering experiences that can become meaningful. The literature on occupational therapy, since the 1990s, has deepened its understanding of narrative practice and the development of meaningful experiences (Hitch et al., 2014b; Zafran, 2020).

All the studies included in this review accessed the meanings constructed by clients in occupational therapy interventions. These are qualitative studies with methodologies that prioritise reflection on the experience that is being lived or that has been lived, such as interviews, written narratives, and focus groups. These methods favor that the meanings can be shared, which highlights the importance of the communication process to access the meaning-making (Ulfseth et al., 2015). Some unexpected discoveries came to light through meaning-making being embodied and defined during the doing process. Arntzen (2018) highlights that the meaning-making processes that emerge in therapeutic interactions are multilayered, mutual, reciprocal, and rapid, and therefore need to be comprehended not only from their cognitive underpinnings but also from their embodied underpinnings.

Doing was highlighted in its importance to the re-acquirement of roles that people used to have, even though it is necessary to learn to perform tasks in new ways, highlighting the impact of new learnings on interpersonal relationships. This review has also shown that when reflecting on doing, new aspects, not previously expected, have been unveiled, as discussed by Gruhl (2017). This result can be analysed considering how much doing leverages new situated occurrences (Ulfseth et al., 2015). From a narrative perspective, Mattingly (1998) argues that meaningful experiences are not passively received, but actively constructed. She stresses the relationship between doing and being, highlighting how much doing can change what people want, enhancing the desire for a different future. Dubouloz (2014) argues that in the "concretudiness" of doing, clients can confront their limitations, exposing their personal emergent meanings and enabling a reflective exploration of such senses. Considering dissonances between doing and thinking, reflective and dialogical opportunities can provide greater integration between these aspects (Mello et al., 2020).

The findings also showed that meaning-making is triggered not only when client's reflect on their limitations, but also when they reflect on new learning. Acquiring new skills and abilities have also triggered reflective processes that enhanced meaningmaking about new, singular, and unusual discoveries. Most of the analysed studies used creative activities for meaning-making insofar as they foster creative processes and opportunities for self-expression and reflection. As discussed by Hansen et al. (2020), creative activities developed in safe and facilitating environments are full of challenges but also of achievable goals that enhance meaning-making. The physical environment 
was valued when it was shown to be adequate for doing, compensating difficulties, as well as favoring the desire to do, instead of inhibiting it (Boniface \& Morgan, 2017).

Human environment was another important focus of the themes, highlighting the importance of doing activities with other people and belonging to a group. In order to facilitate a sense of belonging, our findings show that the human environment must have some special characteristics, such as being able to be supportive; promoting acceptance and recognition of the other for who s/he is and the way s/he can to do; being there to listen to and appreciate the other; being open to establishing new and true relationships; and being open for joy and pleasure. The human environment can be a barrier or facilitator to favor the occupational engagement and social participation of people (Kirsh et al., 2009; Lindsay et al., 2019; Papageorgiou et al., 2016; Ulfseth et al., 2015). This opens space to reflect on our client-centred interventions as well as how and when our intervention needs to extend beyond clinical settings. In two studies in the field of mental health (Leufstadius, 2017; Zafran et al., 2012), the authors directly discussed the need for a more holistic approach so that service users/clients can feel accepted and understood within their communities. People's acceptance of the clients' ways of being and doing was also one of the most expressive results of this review, in addition to what the clients presented as a possibility of feeling whole, present, relaxed, and satisfied with what they do. These results challenge standards of normality, which constantly pressure people to be as society expects (Lindsay et al., 2019).

Thereby, when considering the three constructs related to meaning, as identified by Roepke et al. (2014), this review elucidated that the analyzed interventions unveiled aspects of meaning such as a set of feelings and beliefs that shape world interpretations and give a sense of meaning in life, when participants talked about being themselves, having a sense of perspective in life, and feeling whole through learning about new ways of doing. The construct of meaning related to the purpose of our actions as an aspect of belonging was strongly present in the participants' voices, especially of feeling connected, accepted and recognized by others, even more when doing was related to purposeful actions. Furthermore, this review contributes in particular to the construct related to meaning-making, because even the previous constructs were possible to be unveiled when occupational therapy interventions made it possible to reflect on doing, considering the situation as a whole, triggering processes of making new meanings about the lived experience.

Regarding the professional actions, being a model, fostering hope, and promoting collaboration, autonomy, and positive relationships, were the main aspects to foster the becoming process. Similarly, Weiste (2018) identifies that, in order to establish a successful relational interaction, it is important that occupational therapists provide positive feedback to clients, praise their achievements, encourage and support their progress, and shift their focuses from negative to positive experiences. Arntzen (2018) proposes that occupational therapists adopt an embodied and intersubjective professional reasoning that takes into account the mutual actions and shared meanings that client and therapist bring into the therapeutic situation through their lived bodily 
experiences. Thus, professionals are encouraged to remain attentive to help the clients to find new possible meanings, in order to make bridges with the social contexts.

\section{Conclusions}

This scoping review was conducted following a rigorous and transparent method for mapping this specific area of research. By addressing meaning-making in occupational therapy intervention, this study contributes to clarifying aspects of this process that can be used in occupational therapy interventions to foster becoming. Highlights include (a) for meaning-making to be made explicit, it is important to reflect on doing, on the lived experience of occupational therapy intervention; (b) limitations and disease enhance processes of meaning-making, but also the development of new skills and new abilities; (c) the non-human environment must be adequate for doing, as well as favoring the desire to do, instead of inhibiting it; (d) for belonging processes, the human environment must encourage, respect and appreciate the way of being and doing of the person; (e) professionals are encouraged to remain attentive to establish a positive therapeutic relationship that helps the clients to change their perspectives of meaning and learn to find new possible meanings, in order to make the bridges with the social contexts.

Limitations of this review relate to the fact that scoping reviews discuss the current literature, and, therefore, it is common that the results become outdated quickly given the growing attention to meaning-making in the literature. Our review found only two articles that included children, along with their parents, as research participants. Further research on meaning-making processes in occupational therapy interventions with children are recommended. Studies published in other languages and gray literature have not been included in this review because its focus was to take a broad view of the productions published in English. Review studies on the topic published in other languages are necessary, as well as research on meaning-making in occupational therapy interventions including participants from a broader range of cultures.

Future research also should pursue meaning-making processes through practicebased studies that can elucidate strategies usually used by occupational therapists to foster meaning-making processes. The occupational engagement and social participation can also be studied considering the meanings of people with whom the clients live, including their wider environments such as communities and society. Researchers could also enhance and expand knowledge of how occupational therapists apply different types of professional/clinical reasoning in order to foster meaningmaking in their practices.

\section{References}

Arksey, H., \& O’Malley, L. (2005). Scoping studies: towards a methodological framework. International Journal of Social Research Methodology, 8(1), 19-32. http://dx.doi.org/10.1080/1364557032000119616.

Arntzen, C. (2018). An embodied and intersubjective practice of occupational therapy. OTJR, 38(3), 173-180. http://dx.doi.org/10.1177/1539449217727470. 
Bazyk, S., \& Bazyk, J. (2009). Meaning of occupation-based groups for low-income urban youths attending after-school care. The American Journal of Occupational Therapy, 63(1), 69-80. http://dx.doi.org/10.5014/ajot.63.1.69.

Boniface, G., \& Morgan, D. (2017). The central role of the occupational therapist in facilitating housing adaptations/home modifications for disabled children. British Journal of Occupational Therapy, 80(6), 375-383. http://dx.doi.org/10.1177/0308022616680216.

Chippendale, T., \& Boltz, M. (2015). Living legends: effectiveness of a program to enhance sense of purpose and meaning in life among community-dwelling older adults. American Occupational Therapy Association, 69(4), 6904270010p1. http://dx.doi.org/10.5014/ajot.2015.014894.

Chiu, T. M. L., Wehrmann, S., Reid, D., \& Sinclair, G. (2012). Transforming mother-infant interaction within cultural and caregiving contexts: home-based occupational therapy for preterm infants. Hong Kong Journal of Occupational Therapy, 22(1), 17-24. http://dx.doi.org/10.1016/j.hkjot.2012.04.003.

Cipriani, J., Haley, R., Moravec, E., \& Young, H. (2010). Experience and meaning of group altruistic activities among long-term care residents. British Journal of Occupational Therapy, 73(6), 269-276. http://dx.doi.org/10.4276/030802210X12759925468989.

Dubouloz, C. J. (2014). Transformative occupational therapy: we are wired to be transformers. Canadian Journal of Occupational Therapy, 81(4), 204-212. http://dx.doi.org/10.1177/0008417414554913.

Dubouloz, C. J., Vallerand, J., Laporte, D., Ashe, B., \& Hall, M. (2008). Occupational performance modification and personal change among clients receiving rehabilitation services for rheumatoid arthritis. Australian Occupational Therapy Journal, 55(1), 30-38. http://dx.doi.org/10.1111/j.14401630.2006.00639.x.

Eakman, A. M. (2013). Relationships between meaningful activity, basic psychological needs, and meaning in life: test of the meaningful activity and life meaning model. OTJR, 33(2), 100-109. http://dx.doi.org/10.3928/15394492-20130222-02.

Fletcher, T. S. (2017). Factors that bring meaning to mementos created by elders. Aging \& Mental Health, 21(6), 609-615. http://dx.doi.org/10.1080/13607863.2016.1141284.

Folan, A., Barclay, L., Cooper, C., \& Robinson, M. (2015). Exploring the experience of clients with tetraplegia utilizing assistive technology for computer access. Disability and Rehabilitation: Assistive Technology, 10(1), 46-52. http://dx.doi.org/10.3109/17483107.2013.836686.

Gruhl, K. R. (2017). Becoming visible: exploring the meaning of busking for a person with mental illness. Journal of Occupational Science, 24(2), 193-202. http://dx.doi.org/10.1080/14427591.2016.1247381.

Hammell, K. W. (2004). Dimensions of meaning in the occupations of daily life. Canadian Journal of Occupational Therapy, 71(5), 296-305. http://dx.doi.org/10.1177/000841740407100509.

Hansen, B. W., Erlandsson, L. K., \& Leufstadius, C. (2020). A concept analysis of creative activities as intervention in occupational therapy. Scandinavian Journal of Occupational Therapy, 28(3), 1-15. http://10.1080/11038128.2020.1775884.

Hitch, D., Pépin, G., \& Stagnitti, K. (2014a). In the footsteps of wilcock, part two: the interdependent nature of doing, being, becoming, and belonging. Occupational Therapy in Health Care, 28(3), 247-263. http://dx.doi.org/10.3109/07380577.2014.898115.

Hitch, D., Pépin, G., \& Stagnitti, K. (2014b). In the footsteps of wilcock, part one: the evolution of doing, being, becoming, and belonging. Occupational Therapy in Health Care, 28(3), 231-246. http://dx.doi.org/10.3109/07380577.2014.898114.

Ikiugu, M. N., \& Pollard, N. (2015). Meaningful living through occupation: occupation-based intervention strategies for occupational therapists and scientists. London: Whiting \& Birch.

Kirsh, B., Stergiou-Kita, M., Gewurtz, R., Dawson, D., Krupa, T., Lysaght, R., \& Shaw, L. (2009). From margins to mainstream: what do we know about work integration for persons with brain injury, mental illness and intellectual disability? Work, 32(4), 391-405. http://dx.doi.org/10.3233/WOR-2009-0851.

Leufstadius, C. (2017). Experiences of meaning of occupation at day centers among people with psychiatric disabilities. Scandinavian Journal of Occupational Therapy, 25(3), 180-189. http://dx.doi.org/10.1080/11038128.2017.1325933. 
Lindsay, S., Cagliostro, E., \& McAdam, L. (2019). Meaningful occupations of young adults with muscular dystrophy and other neuromuscular disorders. Canadian Journal of Occupational Therapy, 86(4), 277-288. http://dx.doi.org/10.1177/0008417419832466.

Lindström, M., Sjöström, S., \& Lindberg, M. (2013). Stories of rediscovering agency: home-based occupational therapy for people with severe psychiatric disability. Qualitative Health Research, 23(6), 728-740. http://dx.doi.org/10.1177/1049732313482047.

Lund, K., Argentzell, E., Leufstadius, C., Tjörnstrand, C., \& Eklund, M. (2017). Joining, belonging, and re-valuing: a process of meaning-making through group participation in a mental health lifestyle intervention. Scandinavian Journal of Occupational Therapy, 26(1), 55-68. http://dx.doi.org/10.1080/11038128.2017.1409266.

Mason, J., \& Conneeley, L. (2012). The meaning of participation in an allotment project for fathers of preschool children. British Journal of Occupational Therapy, 75(5), 230-236. http://dx.doi.org/10.4276/030802212X13361458480324.

Mattingly, C. (1998). Healing dramas and clinical plots: the narrative structure of experience. Cambridge: Cambridge University Press.

Mello, A. C. C. M., Dituri, D. R., \& Marcolino, T. Q. (2020). The meaning making of what is meaningful: dialogues with Wilcock and Benetton. Cadernos Brasileiros de Terapia Ocupacional, 28(1), 356-377. http://dx.doi.org/10.4322/2526-8910.ctoen 1896.

Nilsson, I., \& Lundgren, A. (2017). Making meaning around experiences in interventions: identifying meaningfulness in a group-based occupational therapy intervention targeting older people. Ageing and Society, 38(9), 1887-1911. http://dx.doi.org/10.1017/S0144686X17000344.

Papageorgiou, N., Marquis, R., \& Dare, J. (2016). Identifying the enablers and barriers to community participation amongst older adults. British Journal of Occupational Therapy, 79(12), 742-751. http://dx.doi.org/10.1177/0308022616656195.

Rijkers-de Boer, C., Heijsman, A., van Nes, F., \& Abma, T. A. (2017). Professional competence in a health promotion program in the Netherlands. Health Promotion International, 33(6), 958-967. http://dx.doi.org/10.1093/heapro/dax033.

Roberts, A., \& Bannigan, K. (2018). Dimensions of personal meaning from engagement in occupations: a metasynthesis. Canadian Journal of Occupational Therapy, 85(5), 386-396. http://dx.doi.org/10.1177/0008417418820358.

Roepke, A. M., Jayawickreme, E., \& Riffle, O. M. (2014). Meaning and health: a systematic review. Applied Research in Quality of Life, 9(4), 1055-1079. http://dx.doi.org/10.1007/s11482-013-9288-9.

Ulfseth, L. A., Josephsson, S., \& Alsaker, S. (2015). Meaning-making in everyday occupation at a psychiatric centre: a narrative approach. Journal of Occupational Science, 22(4), 422-433. http://dx.doi.org/10.1080/14427591.2014.954662.

Van't Leven, N., de Lange, J., Prick, A. E., \& Pot, A. M. (2016). How do activating interventions fit the personal needs, characteristics and preferences of people with dementia living in the community and their informal caregivers? Dementia, 18(1), 157-177. http://dx.doi.org/10.1177/1471301216662378.

Verdonck, M., Nolan, M., \& Chard, G. (2017). Taking back a little of what you have lost: the meaning of using an Environmental Control System (ECS) for people with high cervical spinal cord injury. Disability and Rehabilitation. Assistive Technology, 13(8), 785-790. http://dx.doi.org/10.1080/17483107.2017.1378392.

Weiste, E. (2018). Relational interaction in occupational therapy: conversation analysis of positive feedback. Scandinavian Journal of Occupational Therapy, 25(1), 44-51. http://dx.doi.org/10.1080/11038128.2017.1282040.

Wilcock, A. A. (2006). An occupational perspective of health. Thorofare: Slack Incorporated.

Zafran, H. (2020). A narrative phenomenological approach to transformative learning: lessons from occupational therapy reasoning in educational practice. American Occupational Therapy Association, 74(1), 1-6. http://dx.doi.org/10.5014/ajot.2020.033100.

Zafran, H., Tallant, B., \& Gelinas, I. (2012). A first-person exploration of the experience of academic reintegration after first episode psychosis. International Journal of Psychosocial Rehabilitation, 16(1), 29-46. 


\section{Author's Contributions}

Ana Carolina Carreira de Mello and Taís Quevedo Marcolino contributed to the conception of the work and carried out the review study. Angélica da Silva Araujo cross checked the study selection for accuracy. Angélica da Silva Araujo and Ana Lucia Borges da Costa contributed critically to the interpretation, presentation and discussion of the

findings. All authors approved the final version of the text.

\section{Funding Source}

Grant 001, Brazilian Federal Foundation for Support and Evaluation of Graduate Education (CAPES - Coordenação de Aperfeiçoamento de Pessoal de Nível Superior, Brasil).

\section{Corresponding author}

Ana Carolina Carreira de Mello.

e-mail: anacarolinacmello@gmail.com

\section{Section editor}

Profa. Dra. Tatiana Pontes 